\title{
Shoulder Surgery
}

\author{
Marius M. Scarlat
}

Received: 14 December 2014 / Accepted: 14 December 2014 / Published online: 15 January 2015

(C) SICOT aisbl 2015

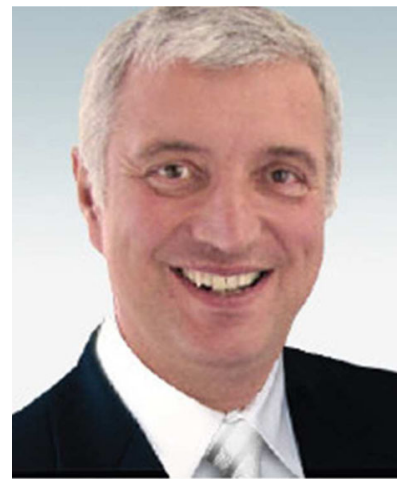

It is a privilege for an editor to be the host of a Special Edition. One year ago the Board of International Orthopaedics decided to dedicate a special edition to my field of interest and I accepted with honour and pride to take care of this issue. There were some difficulties. The main difficulty concerned the authors who are usually busy and very often late with submissions, revisions, adding supplementary materials and so on. Other challenges were the variable quality of the papers, how to get a fair distribution and selection between the submitted manuscripts. There is a plethora of authors from many countries, different schools and different directions of development. As the Journal of the SICOT, "International Orthopaedics" is concerned about the latest trend or great studies coming from services with substantial experience in shoulder surgery, as well as in the services from the developing countries that take care of millions of patients with limited equipment and material. You will find in this issue both types of

M. M. Scarlat $(\bowtie)$

Chirurgie Orthopédique et Traumatologique, Clinique Chirurgicale St Michel, Toulon, France

e-mail:mscarlat@gmail.com reports and you will be amazed about how experienced some services from the developing world are. The interest of a reader focuses sometimes on clinical papers, evidence-based results with one or other procedure, but also on basic research. There are also papers concerning the biology of repair or biomechanics. Some procedures are not well known, others are with uncertain outcome at long term, and some repairs or fixations have better mechanic properties, but biology and "in vivo" behaviour is the final judge.

If your curiosity pushes you to read journals from a few decades ago, you may be surprised about how much the interest of the editors and of the readers changed. A specialized orthopaedic journal 40 years ago was including papers about how much acromion to remove in order to obtain a good subacromial decompression, how to do a posterior approach with acromionectomy for performing an arthroplasty or how to do glenohumeral fusion in cases of pseudoparalytic shoulders. Arthroscopy was nonexistent. All this changed because of huge amounts of work and progress coming from different regions of the globe. The change comes with criticism. A couple of years ago I was listening to a presentation from a shoulder specialist who was teaching that a well-known paper published by Charles Neer in the early 1980s was incorrectly melting unidirectional instability with laxity in a series of patients having capsular shift. It seemed to me that it was like criticizing Lindbergh because he crossed the Atlantic without GPS! But the human brain needs comparison to improve and to understand. In our days the pathologic findings are quite well defined because we have better biomechanics and we learn from giants like Neer, Matsen, Rockwood, Walch and Grammont (the list is far from complete) who devote their lives working and providing high quality research, papers, textbooks and results on substantial series of patients. The development of academic societies like the European Shoulder and Elbow Surgeons Society, the American Shoulder and Elbow Surgeons, and other national societies of shoulder surgery all over the 
globe provided a logic and scientific environment that helped the exchange of information and formation of the younger generation. There are now several specialized shoulder periodicals but also many chapters in general orthopaedic publications. There are shoulder surgery services in all the major orthopaedic departments all over the planet. I was recently participating in a shoulder session at the SICOT world congress in Brazil. The quality of the papers coming from Brazil, Chile and Portugal was exceptional and the academic level of discussions with the specialists from different parts of the world was outstanding! Who could have imagined this 40 years ago?

However, for an individual surgeon or scientist the process of becoming a specialist is a personal journey! And this personal journey is marked by some exceptional individuals who share their time and energy with the candidate to pass on knowledge! This was my case and this was probably the case with the vast majority of us. This is why I want to dedicate this special editorial to the man who helped me to become a shoulder surgeon. Douglas T. Harryman II (Fig. 1) was the most brilliant specialist of his generation; his work is still cited and acknowledged over the years. Unfortunately, Doug passed away at an age when many surgeons start to publish, after having authored major papers, academic course lectures and books! In 1998 he was regularly performing arthroscopic cuff repair and all the gamut of open and minimally invasive shoulder surgeries in all types of pathologies, including the neurologic shoulder and difficult reconstructions. Having the opportunity to learn and improve my status with this particular gentleman was for me - as for all the other fellows who worked in

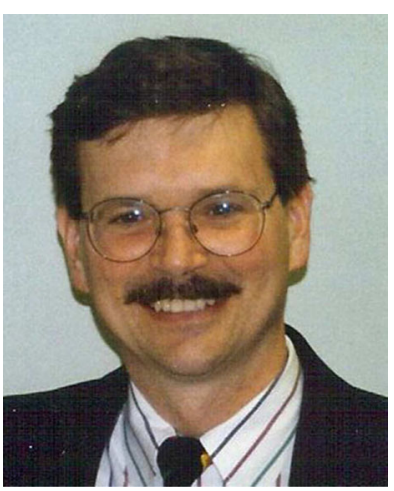

Douglas T. Harryman II in 1998

the famous University of Washington in Seattle Shoulder and Elbow Service chaired by Professor Rick Matsen - a lifetime achievement, a cornerstone in the career and in life. This exceptional surgeon offered to all his colleagues and fellows an unperishable model for learning and improving, based on hard work, personal experience, good sense and encyclopaedic knowledge. This man changed my life for good and made me better. Dedicating this work to his memory is a privilege for me and for the other fellows and colleagues who worked with him.

I took the liberty in this issue to invite some famous names and also representatives from different orthopaedic or trauma shoulder specialists. I hope that we provided a selection of papers that satisfy your interest for reading about shoulder. 